\title{
The Effects of $\mathrm{PO}_{4}{ }^{3-}$ Removal from Aqueous Solution with Varied Concentrations of Metal Oxides in Steel Slag Filter System
}

\author{
Rafidah Hamdan, ${ }^{*}$ Nur Ain Nazirah Mohd Arshad and Siti Zu Nurain Ahmad \\ Department of Water and Environmental Engineering, Faculty of Civil and \\ Environmental Engineering, Universiti Tun Hussein Onn Malaysia, \\ 86400 Parit Raja, Batu Pahat, Johor, Malaysia \\ *Corresponding author: rafidahh@uthm.edu.my
}

Published online: 25 October 2018

To cite this article: Hamdan, R., Mohd Arshad, N. A. N. \& Ahmad, S. Z. N. (2018). The effects of $\mathrm{PO}_{4}{ }^{3-}$ removal from aqueous solution with varied concentrations of metal oxides in steel slag filter system. J. Phys. Sci., 29(Supp. 3), 71-80, https://doi.org/10.21315/ jps2018.29.s3.9

To link to this article: https://doi.org/10.21315/jps2018.29.s3.9

\begin{abstract}
High amount of orthophosphate will accelerate the growth of autotrophs and eutrophication will occur. This phenomenon decreases the water quality and as a result may increase the cost of water treatment for drinking water. The overabundance of orthophosphate occurs when untreated or inadequately-treated wastewater from domestic and industrial activities is released into water bodies. Conventional treatment has been developed to treat wastewater. However, it is not effective for phosphorus removal, hence, high-cost advanced treatment is needed to remove phosphorus. Thus, alternative low-cost treatments for phosphorus removal are needed. Therefore, this study was conducted to understand and investigate the mechanisms of phosphorus removal using two different setups of steel slag filter, Set 1 for high Fe and Set 2 for high Ca. The study was operated at different $\mathrm{pH}$ values of 3, 5, 7, 9 and 11 under aerated and unaerated conditions. The samples of steel slag from 12 filters that has been run for three months for each set were semi-quantitatively analysed using scanning electron microscope-energy dispersive X-ray (SEM-EDX) to identify the adsorption of phosphate ion on the surface of the steel slag. The results of SEM-EDX studies showed that adsorption mechanism of phosphate removal takes place on the surface of the steel slag. The precipitates in the steel slag filters were collected and analysed for X-ray diffraction (XRD) for chemical compound identification and the precipitates were confirmed to be $\mathrm{Fe}_{3} \mathrm{O}_{4}$, a precursor of iron phosphate related compound.
\end{abstract}

Keywords: Eutrophication, phosphate removal mechanism, steel slag filter, metal oxides, aqueous solution 


\section{INTRODUCTION}

Wastewater from domestic, industrial and agricultural activities contains high amount of chemical by-products and nutrients. The high level presence of nutrients will damage the water bodies, thus promoting the formation of eutrophication. Eutrophication is the effect caused by the increase in concentration of plant nutrients, usually nitrogen and phosphorus. The overabundance of nutrients in water accelerates the growth of algae, decreasing the water quality, and resulting in the significant increase of water treatment cost at treatment plants for surface water.

Phosphorus removal systems are commonly installed in wastewater treatment plants as an advanced treatment system, depending on the type of wastewater being treated. However, the costly implementation of such system may present as a challenge. Therefore, research on low-cost techniques to upgrade phosporus removal has become a priority for scientists in the last two decades. Several studies have demonstrated that filtration through replaceable materials with high affinities for phosphorus binding is a viable technique to upgrade phosphorus removal in wastewater, such as using steel slag. ${ }^{1}$ Steel slag filter system has emerged as an alternative method to the conventional treatment system. However, the $\mathrm{pH}$ effects on the removal mechanisms of phosphorus in steel slag filter system is still lacking. Therefore, this study is conducted to determine the mechanisms of phosphorus removal at various $\mathrm{pH}$ using steel slag filter.

Wastewater or sewage originates from a variety of domestic, industrial and storm sewage sources. Domestic wastewater is defined as wastewater from household water use which comes primarily from individuals and does not include industrial or agricultural wastewater. ${ }^{2}$ Domestic wastewater is one of the main contributors to the formation of nutrients loading in water system. The presence of phosphorus in the wastewater increases the amount of natural phosphorus in the water system, causing an excessive amount of the compound. An over-abundance of phosphorus can over-stimulate plant and algae growth in such a way that they create water quality problems, mainly eutrophication. Eutrophication is a term that describes the biological effects from increasing concentration of plant nutrients, usually nitrogen and phosphorus on aquatic ecosystems. ${ }^{3}$

The amount of phosphate in wastewater is quite in abundance. Phosphorus compound cannot be found in wastewater as an element. It is predominantly found in wastewater as phosphate ions. Therefore, advance treatment for phosphorus removal is always required for wastewater treatment plant. Hence, multiple studies have been conducted on the removal of phosphorus in wastewater using safe, 
non-toxic materials as a substrate in phosphorus removal in water treatment plants. The ideal phosphorus sorbing materials (PSMs) for use in various practices should be free, non-toxic, industrial by-products and are generated locally. They should also be widely available and potentially useful as soil amendments once saturated with phosphorus. ${ }^{4,5}$ The presence of ferum, calcium, aluminium and magnesium in the materials used are expected to promote the phosphate removal. Alum, gypsum and fly ash were studied as phosphorus sorbing material treating the streamside cattle loafing areas. The results showed that alum is a great material in removing phosphorus in water system. Previous studies using different materials such as light expanded clay, crushed marble and calcite were used as the media to explore the new insight on their phosphorus binding capacity. 6,7

Phosphorus removal involves two mechanisms, namely adsorption and precipitation. The effectiveness of the mechanisms depends on how the PSMs will be applied or used, and their physical properties such as particle size and hydraulic conductivity of the material. Appropriate condition of $\mathrm{pH}$ also affects the removal mechanism of phosphorus and must be taken into consideration when predicting which PSMs are more effective. A number of researchers have interpreted adsorption onto metal oxides or oxyhydroxides on the surface of slag to be a significant phosphorus removal mechanism. Adsorption is a surface-based process where a film of adsorbate is created on the surface. The removal mechanism can be done with the presence of $\mathrm{Fe}, \mathrm{Ca}, \mathrm{Mg}$ and $\mathrm{Al}$ because these minerals adsorb inorganic ions such as $\mathrm{PO}_{4}{ }^{3-}$ from solution. The removal of phosphorus by adsorption occurs in an alkaline $\mathrm{pH}(\mathrm{pH}>9)$ with the high amount of Fe present in the solution. Phosphate ions $\left(\mathrm{PO}_{4}{ }^{3-}\right)$ in effluents are removed from solution by adsorption onto amorphous oxides or oxyhydroxides which dominate the porous matrix and surface coating of the slag. However, in the presence of high $\mathrm{Ca}$, the adsorption occurs in an acidic condition.

As for precipitation mechanism, Fe and Ca salts will be formed in the presence of orthophosphate which were described as the formation of crystalline precipitates. Phosphate removal occurs through calcium phosphate precipitation at high $\mathrm{pH}$ in the presence of high calcium ions in the media. The removal process occurs due to the precipitation of phosphate with exchangeable and dissolved $\mathrm{Ca}^{2+}$. The liberated $\mathrm{Ca}^{2+}$ obtained from the exchange site or from the dissolution of $\mathrm{CaCO}_{3}, \mathrm{CaO}$ and $\mathrm{Ca}(\mathrm{OH})_{2}$ are preferably precipitated by phosphate in a neutral to alkaline solution. Under neutral to acidic condition, the removal of phosphate is probably due to the ion exchange between phosphate hydrolysis products $24(\mathrm{HPO},-\mathrm{HPO})^{-2}$ as well as the precipitation of the metallic salts of $\mathrm{Al}^{3+}, \mathrm{Ca}^{2+}$ and $\mathrm{Fe}^{3+}$ released by slag with phosphate in the solution, which form stable phosphate precipitates such as hydroxyapatite. A few research works have been done using steel slag as filtration 
media in treating wastewater to remove phosphorus. Steel slag contains high amount of $\mathrm{Fe}^{2+}, \mathrm{Ca}^{2+}$ and $\mathrm{Mg}^{2+}$ which make them have high affinities in removing phosphorus.

\section{EXPERIMENTAL}

Two types of steel slag have been selected due to their chemical compositions; either high in $\mathrm{Fe}$ or $\mathrm{Ca}$ for varied metal oxides study of phosphate removal in synthetic wastewater. The samples from steel slag filter systems with different $\mathrm{pH}$ value $(3,5,7,9$ and 11) were brought for surface analysis using Variable Pressure SEM (JEOL JSM-IT300LV, United States) analyser to identify the presence of phosphorus element, which indicates the adsorption of phosphate ions onto the surface of the steel slag. Finally, precipitate formed within the steel slag filter was examined using XRD (SmartLab Rigaku) analysis to identify the compound.

\section{RESULTS AND DISCUSSION}

The characterisation of steel slag is needed to identify the composition of the steel slag, i.e., the percentage amount of $\mathrm{Ca}, \mathrm{Mg}, \mathrm{Fe}$ and any other ions present. The determination of the composition of the media is done using XRF analysis and the results are presented below for both sets. The results in Table 1 shows the characterisation of steel slag media with high $\mathrm{Fe}$ and high $\mathrm{Ca}$.

Table 1: XRF Analysis of steel slag samples.

\begin{tabular}{lcc}
\hline Element & Concentration (\%)-Set 1 & Concentration (\%) - Set 2 \\
\hline $\mathrm{Fe}_{2} \mathrm{O}_{3}$ & 38.20 & 49.50 \\
$\mathrm{SiO}_{2}$ & 15.20 & 18.00 \\
$\mathrm{MgO}$ & 3.22 & 0.10 \\
$\mathrm{C}$ & 1.00 & 4.32 \\
$\mathrm{SO}_{3}$ & 0.28 & 2.58 \\
$\mathrm{Al}_{2} \mathrm{O}_{3}$ & 7.03 & 2.23 \\
$\mathrm{CaO}$ & 20.40 & 1.64 \\
$\mathrm{MnO}^{\mathrm{TiO}}$ & 5.19 & 0.38 \\
\hline
\end{tabular}




\subsection{Effects of pH on Phosphate Removal Mechanism in High Fe and High Ca Steel Slag}

Results from this study show that the removal mechanisms of phosphate within the steel slag systems were $\mathrm{pH}$ dependent. As for the filter with $\mathrm{pH}$ neutral to alkaline, the dominant mechanism was seen to be adsorption whereas at $\mathrm{pH}$ neutral to acidic filter system, precipitation was found to be more dominant. As observed in the high Fe filter of $\mathrm{pH} 11$ after 12 weeks of experiment, it could be seen clearly that there was a formation of brownish layer on the surface of the steel slag media. The brownish layer were expected to be $\mathrm{PO}_{4}{ }^{3-}$ ion adsorbed to the surface layer of steel slag reacting with the $\mathrm{Fe}^{2+}$ ion in the steel slag. This shows that the adsorption process occur at alkaline condition, seen in Figure 1(a).

Furthermore, in the filter with neutral to acidic $\mathrm{pH}$ value, precipitation was expected to occur. The $\mathrm{Fe}^{2+}$ ions contained in the steel slag were leached out and reacted with $\mathrm{PO}_{4}{ }^{3-}$, forming $\mathrm{Fe}$ phosphate compound, $\mathrm{Fe}_{3}\left(\mathrm{PO}_{4}\right)_{2}$. The formation of precipitates could be observed in the unaerated $\mathrm{pH} 3$ filter system after 12 weeks of experiment as shown in Figure 1(b). However, the layer of $\mathrm{PO}_{4}{ }^{3-}$ was also visible on the surface of steel slag in the filter, indicating that the adsorption mechanism also takes place but not as much as precipitation. Therefore, at lower $\mathrm{pH}$, both mechanisms were possible to take place thus increasing the efficiency of phosphate removal.

To further confirm the adsorption mechanism at high $\mathrm{pH}$, the surface of the high $\mathrm{Fe}$ steel slag was analysed using variable pressure-SEM analyser. Figure 2 shows the SEM micrograph and spectrum of fresh steel slag before treatment which showed no presence of phosphate. Meanwhile, Figure 3 shows the SEM micrograph and spectrum of high Fe steel slag with $9.6 \%$ of phosphate detected on the surface, which proves that some $\mathrm{PO}_{4}{ }^{3-}$ were adsorbed onto the surface of the steel slag. The yellow crystalline identified by SEM was the phosporus element attached to the surface of the steel slag. In addition, the precipitates formed at $\mathrm{pH} 3$ were expected to be $\mathrm{Fe}_{3}\left(\mathrm{PO}_{4}\right)_{2}$. However, the results showed that the precipitated compounds were $\mathrm{Fe}_{3} \mathrm{O}_{4}$ as shown in Figure 4. This shows a contradiction to the expected compound forms but deduction can be made that the removal of phosphate did occur through precipitation. The $\mathrm{Fe}_{3} \mathrm{O}_{4}$ is considered as a precursor of iron phosphate related compound since a longer time is needed for the $\mathrm{Fe}_{3}\left(\mathrm{PO}_{4}\right)_{2}$ compounds to be formed. 


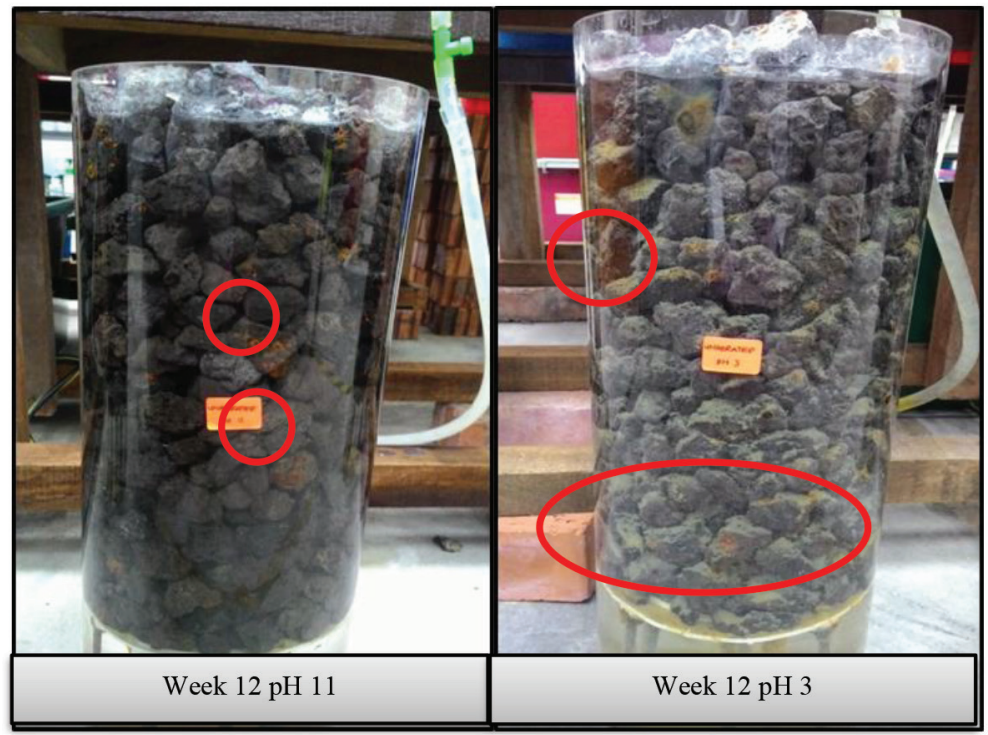

(a)

(b)

Figure 1: Adsorption mechanism on surface of (a) steel slag in $\mathrm{pH}$ 11, and (b) precipitation mechanism at the bottom of the filter in $\mathrm{pH} 3$, high Fe steel slag system.

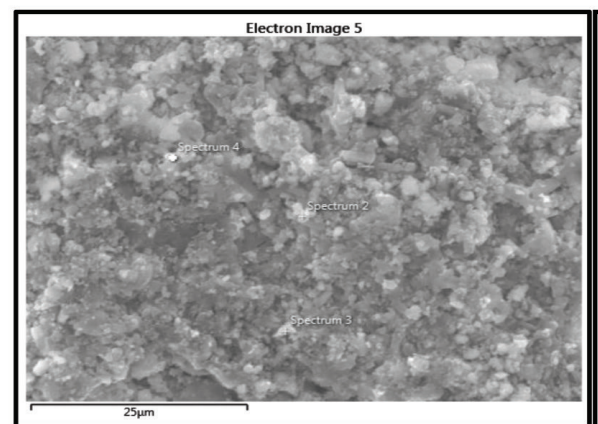

(a)

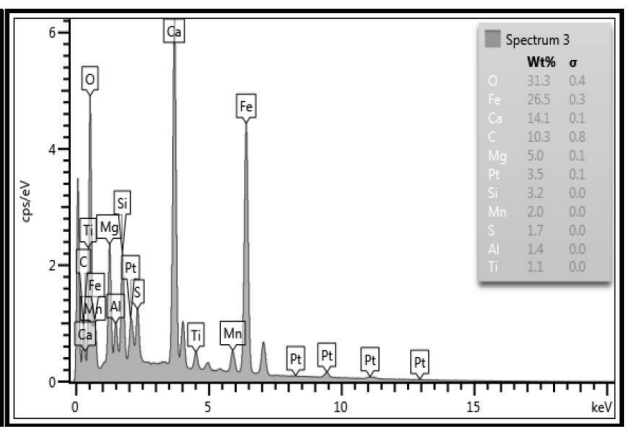

(b)

Figure 2: SEM micrograph of the particles of high Fe steel slag (a) before phosphate adsorption, and (b) its spectrum. 


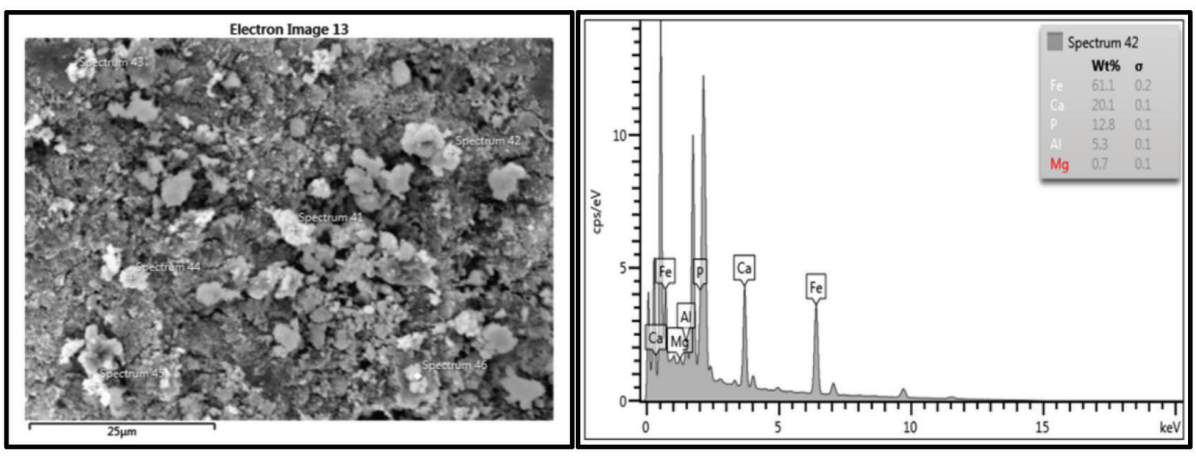

(a)

(b)

Figure 3: SEM micrograph of the particles of high Fe steel slag (a) after process of adsorption occurs, and (b) its spectrum at pH 9.

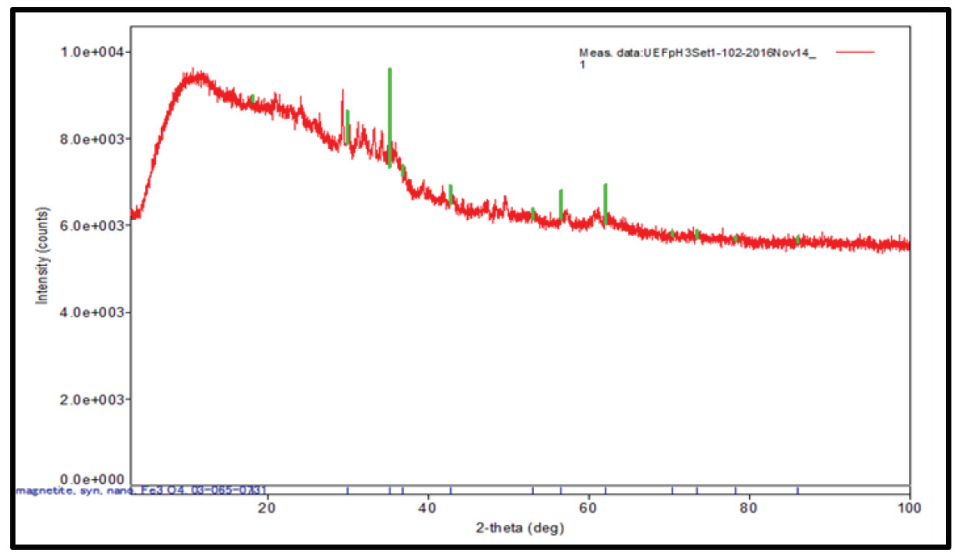

Figure 4: XRD analysis showed the peak were $\mathrm{Fe}_{3} \mathrm{O}_{4}$ for high $\mathrm{Fe}$ steel slag at $\mathrm{pH} 3$.

In steel slag with high amount of $\mathrm{Ca}, \mathrm{pH}$ values of the solution also contributed in enhancing the removal of phosphate. In the solution with neutral to alkaline $\mathrm{pH}$, precipitation was supposed to occur through the formation of calcium phosphate, $\mathrm{Ca}_{3}\left(\mathrm{PO}_{4}\right)_{2}$ as shown in Figure 5. The calcium was leached out from the steel slag due to the dissolution of $\mathrm{CaO}$ present in the steel slag and reacted with the $\mathrm{PO}_{4}{ }^{3-}$ forming the white precipitation expected to be $\mathrm{Ca}_{3}\left(\mathrm{PO}_{4}\right)_{2}$. As observed after 12 weeks of experiment, white precipitates were formed at the bottom of the $\mathrm{pH} 11$ filter which indicated that the removal of phosphate was through precipitation. However, the results obtained from XRD analysis showed that the white precipitates formed was calcite $\left(\mathrm{CaCO}_{3}\right)$ as shown in Figure 6. This was probably due to the reaction between dissolved $\mathrm{Ca}^{2+}$ with $\mathrm{CO}_{3}{ }^{-}$presence in the solution since in alkaline solution, $\mathrm{HCO}_{3}{ }^{-}$and $\mathrm{CO}_{3}{ }^{2-}$ were the main ion constituents. 
The $\mathrm{HCO}_{3}^{-}$was dissolved and ion exchange occurred to form the precipitates. For solution with neutral to acidic $\mathrm{pH}$, adsorption mechanism occurred. The $\mathrm{PO}_{4}{ }^{3-}$ was adsorbed onto the surfaces of steel slag due to the presence of oxy-hydroxide which dominated the porous matrix and surface coating of the slag. The white crystals on the slag surfaces could be seen after 12 weeks of experiment on filter of $\mathrm{pH}$ 3. Based on SEM analysis, the adsorption of $\mathrm{PO}_{4}{ }^{3-}$ was proven since the presence of phosporus element was detected on the slag surfaces through the formation of white precipitates, seen in Figure 7.

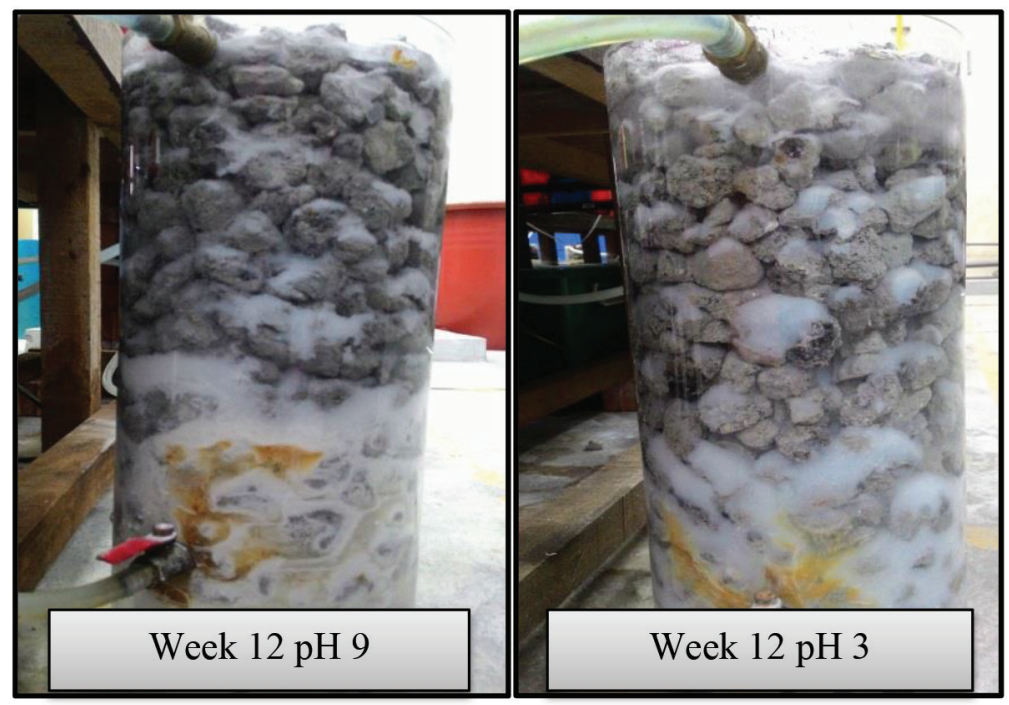

(a)

(b)

Figure 5: Illustrations of (a) precipitation mechanism at the bottom of the filter in $\mathrm{pH} 9$, and (b) adsorption mechanism on surface of steel slag in $\mathrm{pH} 3$, high Ca steel slag system. 


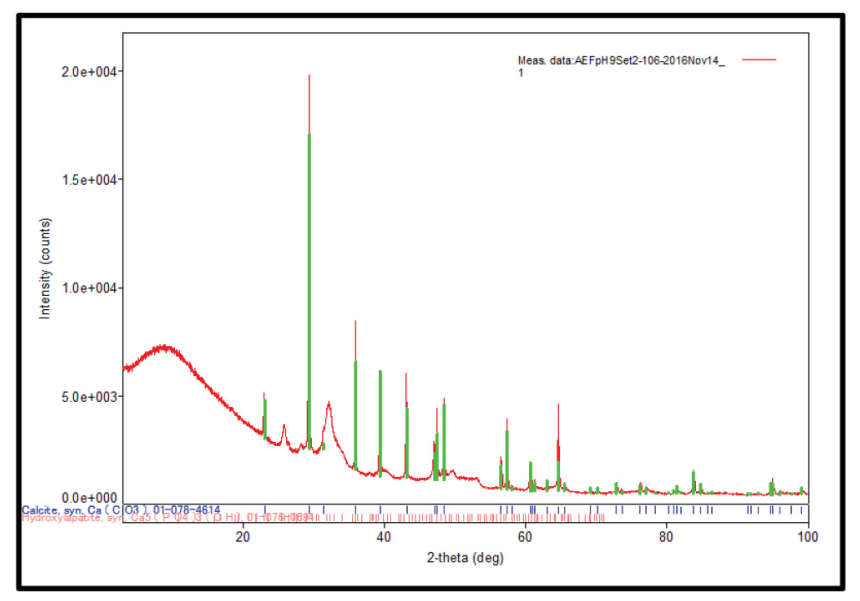

Figure 6: XRD analysis showed the calcite peak for high calcium steel slag at $\mathrm{pH} 9$.

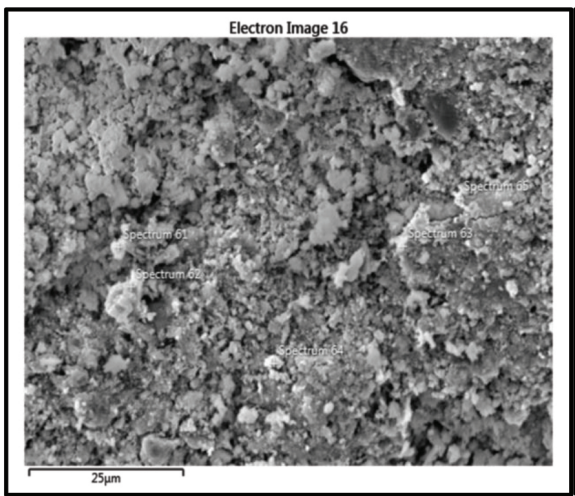

(a)

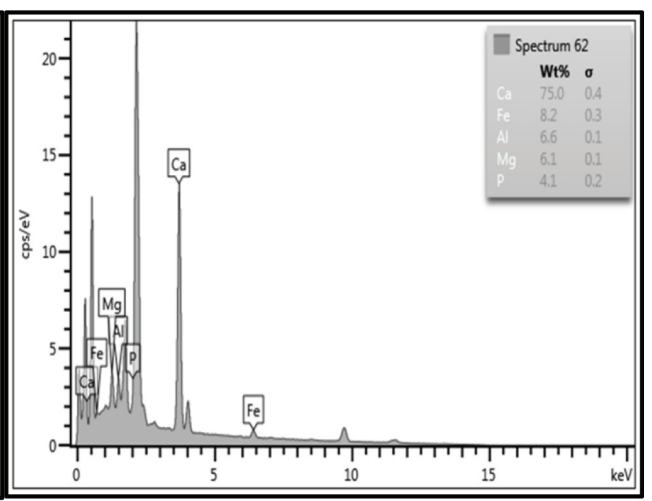

(b)

Figure 7: SEM micrograph of the particles of high Ca steel slag (a) after process of adsorption occurs, and (b) its spectrum at $\mathrm{pH} 3$ filter.

\section{CONCLUSION}

This study showed that both aerated and unaerated systems were efficient in removing phosphate from wastewater but the unaerated system performed slightly better than aerated system in both high Fe and high Ca steel slag filter. However, the effects of $\mathrm{pH}$ were a major contributor in the types of mechanisms involved in phosphate removal. The mechanisms identified from these experiments for high Fe steel filter were adsorption and precipitation while high Ca steel slag filters was 
only adsorption, based on SEM-EDX analysis and precipitation based on XRD analysis.

\section{ACKNOWLEDGEMENTS}

The authors are grateful for the funding provided by Ministry of Higher Education and University Tun Hussein Onn Malaysia, under Fundamental Research Grant Scheme (FRGS) VOT 1613.

\section{REFERENCES}

1. Barca, C. et al. (2013). Steel slag filters to upgrade phosphorus removal in constructed wetlands: Two years of field experiments. J. Environ. Sci. Technol., 47(1), 549-556, https://doi.org/10.1021/es303778t.

2. Doorn, M. R. J. et al. (2006). Wastewater treatment and discharge. Guidel. Natl. Greenh. Gas Invent., 1-28.

3. Loch, B. (1992). Eutrophication of freshwaters. New York: Wiley.

4. Rössle, W. H. \& Pretorius, W. A. (2001). A review of characterisation requirements for in-line prefermenters. Paper 1: Wastewater characterisation. Water SA, 27, 413-422, https://doi.org/10.4314/wsa.v27i3.4985.

5. Leader, J. W., Dunne, E. J. \& Reddy, K. R. (2008). Phosphorus sorbing materials: Sorption dynamics and physicochemical characteristics. $J$. Environ. Qual., 37, 174-181, https://doi.org/10.2134/jeq2007.0148.

6. Brix, H. et al. (2001). Media selection for sustainable phosphorus removal in subsurface flow constructed wetlands. Water Sci. Technol., 44(11-12), 47-54, https://doi.org/10.2166/wst.2001.0808.

7. Penn, C. J. \& Bryant, R. B. (2006). Application of phosphorus sorbing materials to streamside cattle loafing. J. Soil Water Cons., 61, 303-310. 